\title{
A Model of Situational Willingness to Communicate (WTC) in the Study Abroad Context
}

\author{
Graham Robson ${ }^{1}$ \\ ${ }^{1}$ International Tourism Department, Toyo University, Tokyo, Japan \\ Correspondence: Graham Robson, International Tourism Department, Toyo University, Hakusan 5-28-20, \\ Bunkyo Ward, 112-8606 Tokyo, Japan. Tel: 81-03-3945-8264. E-mail: robson@toyo.jp
}

Received: April 25, 2015 Accepted: May 30, 2015 Online Published: September 28, 2015

doi:10.5539/ies.v8n10p114 URL: http://dx.doi.org/10.5539/ies.v8n10p114

\begin{abstract}
The use of structural modeling has helped to explain constructs leading to Willingness to Communicate (WTC) in L1 and L2 contexts. When WTC was conceptualized as a trait in the L1, more personality variables were used in models. When WTC moved into the realm of second language, researchers still used trait measurements to explain the construct, along with motivation and other communication-related variables. More recently, researchers recognize that WTC is also a situational variable and some researchers have created measurement tools accordingly. This study focuses on 67 students studying on a pre-university academic course in English and tests a structural model using classroom constructs as they are deemed the most important for communication in the classroom to predict WTC. Also, the model uses a teacher score to measure the relationship between self-report WTC and actual classroom communication. The model was found to have reasonable levels of fit, showing the importance of classroom variables in situational WTC in the second language context.
\end{abstract}

Keywords: willingness to communicate, structural models, classroom constructs, study abroad

\section{Introduction}

There is a distinction between second and foreign language settings that arises from more opportunities for interaction and communication in the second language context (Oxford \& Shearin, 1994). However, it can be hard even for study abroad students to move beyond the classroom and use English actively in the L2 community. Therefore, the classroom reaffirms itself in both second and foreign language settings as an important place to conduct research, as it can offer the main, and sometimes only, interaction opportunity in the target language.

Within the classroom, one of the major goals of learning should be to engender in learners a willingness to communicate, or WTC, (MacIntyre, Clément, Dörnyei, \& Noels, 1998, p. 547). If learners can develop a willingness to communicate in class, they will hopefully take those habits outside the classroom and enact them in the real world. However, there are a number of different forces that act on the learner that may increase or decrease the learner's willingness to communicate in the classroom.

The concept of willingness to communicate (WTC) was originally conceived as a measure of how disposed native speakers of English were to engage voluntarily in classroom communication (McCroskey \& Baer, 1985). This concept has also been investigated by second language researchers in many different contexts with many different age groups through the process of advanced statistical analyses, like Structural Equational Modeling (SEM).

The benefits of employing SEM are that it can reduce measurement error, which is estimated and leaving only common variance in the model. SEM also allows the researcher to simultaneously examine the relationships of all the constructs specified in a model (Tabachnick \& Fidell, 2007, p. 679). This means that once the theory has been formulated in a model for testing, the model can be retested to improve the reliability and strength of relationship among the key constructs.

The SEM research conducted in the field of WTC has tended to see the construct as a trait, hypothesizing WTC as stable across different situations and with different interlocutors, relying heavily on L1 trait instruments. However, recently starting with MacIntyre et al. (1998), WTC has been reconceptualized as a situational construct (Kang, 2005; Peng \& Woodrow, 2010). Currently the number of studies that have employed situational variables in WTC models is small. By continuing to use trait measurements for situational models, the validity of 
any results can be called into question. In order to better understand the forces that impact on learning in the classroom in a particular situation, which can shape the WTC of a learner, more models are needed that make use of situational variables (Weaver, 2010).

\section{Literature Review}

This short literature review addresses how WTC has been researched in models in the L1 and L2 contexts.

\subsection{WTC Models in the L1}

WTC was originally conceptualized as a personality-based predisposition (McCroskey \& Baer, 1985) in L1 speakers of English. Therefore, models of WTC in the L1 were developed through a hierarchy of antecedents starting with personality traits and moved towards more communication-related variables, like Communication Apprehension and Perceived Competence (MacIntyre, 1994; MacIntyre, Babin, \& Clément, 1999).

\subsection{L2 Models Employing Trait WTC}

Many of the models first created to describe WTC in the second language used an L1 measure of WTC created by McCroskey and Baer (1985), seeing WTC as a trait variable. The models of trait WTC were heavily influenced by the Socio-Educational model (Gardner, 1985), which described attitudes and integrative reasons for studying English concerned with the desire to meet persons from the second language community, as well as attitudes toward the second language community. Studies found that motivation and communication variables were powerful and significant predictors of WTC (Hashimoto, 2002; MacIntyre \& Charos, 1996).

Moving from second language to foreign language setting, the Intergrative orientation was revised into International Posture (Yashima, 2002), a construct consisting of Interest in Foreign Affairs, Interest in Working Abroad, Cultural Friendship (similar to integrative motivation), and Approach/Avoidance of L2 English. Studies found that students with higher levels of International Posture also had significantly higher levels of WTC in the foreign language setting (Kim, 2004; Yashima, 2002; Yashima, Zenuke-Nishide, \& Shimizu, 2004).

\subsection{Situational WTC in the Second Language}

Whereas trait-like WTC, as described in the L1 literature, has the potential to affect people in all communication settings, there are certain situational constraints that affect what happens in a given situation. As far back as 1994, MacIntyre proposed that future researchers should combine personality variables with situational variables to measure WTC (p. 140). To this end, one of the first major models of L2 WTC (MacIntyre et al. 1998), and one that would greatly influence second language research, treated WTC as both a mixture of "transient and enduring influences" (p. 546).

MacIntyre et al. (1998) proposed a number of personalities, affective and situational constructs that fit into a theoretical model with six layers (see Figure 1). At the bottom of the model are layers that are more trait-like and enduring in nature, like Personality and Intergroup Attitudes. At the top of the model more changeable situational factors appear such as the Desire to Communicate with a Specific Person and the Self-Confidence of the speaker at the time of communication. These variables are hypothesized to lead to WTC, and to lead eventually to the amount of communication undertaken by the learner, as expressed by L2 Use in the model. By hypothesizing WTC in this way, the researchers claimed that WTC can be used to address pedagogical concerns, such as why some students speak in language classes, while others do not. This will lead to a deeper understanding of important factors influencing classroom communication (p. 558).

There are a number of issues in WTC research which are still being addressed, two of which are the use of situational constructs to explain statistical models and whether a student's WTC will actually be indicative of how much a student communicates. 


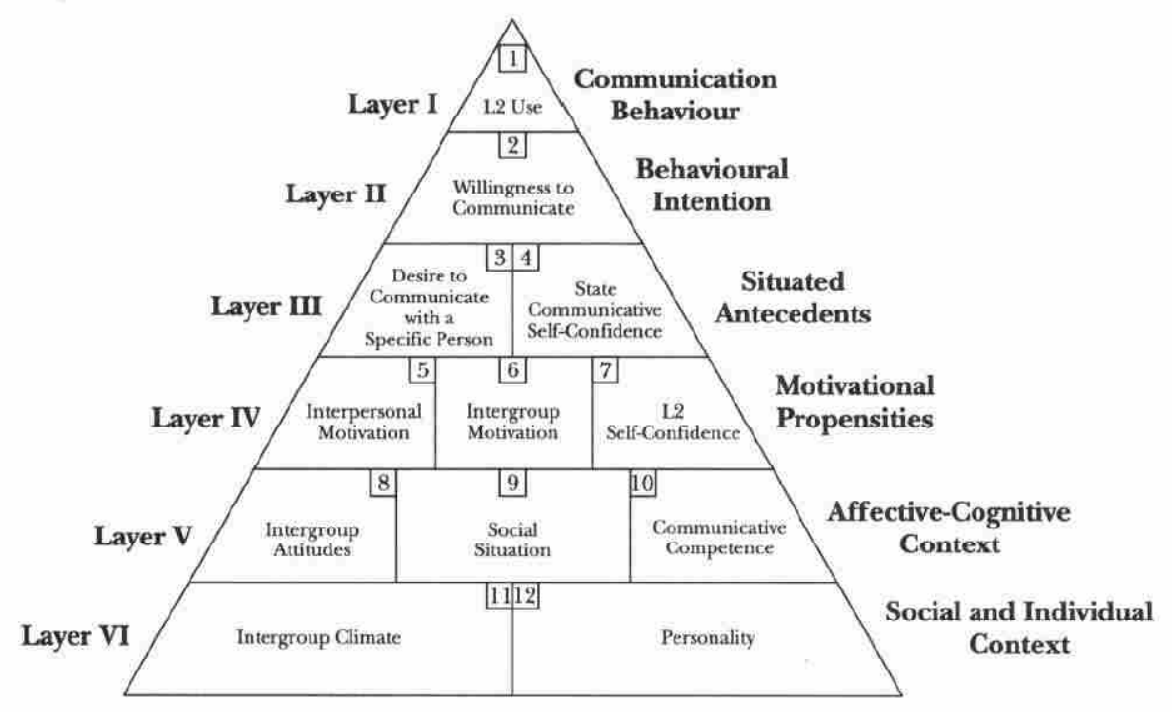

Figure 1. Heuristic model of variables influencing WTC (Macintyre, Clément, Dörnyei, \& Noels, 1998, p. 547).

\subsection{L2 Models Employing Situational WTC}

A number of L2 researchers have used more situated variables. Along with MacIntyre et al. (1998), Wen and Clément (2003) hypothesized that mediating Desire and Willingness to Communicate are factors that MacIntyre et al. (1998) proposed to be more distant from the communication event. These include the Social Context, including In-Group Identity and Group Cohesiveness, and Teacher Involvement; affective perceptions such as Self-Confidence in communication (inhibited monitor) and expectation that the task undertaken will receive a positive evaluation. The two theoretical models were not data-driven, but influenced subsequent situational WTC models (Kang, 2005; Peng \& Woodrow, 2010).

Other quantitative researchers began using measurements that reflected what happened in the classroom. Matsuoka (2005) tested a structural model with 164 Japanese students. Her model predicted WTC would be determined by International Posture and Self-Efficacy, which was hypothesized to be comprised of Motivational Intensity and Perceived Competence. Self-Efficacy, a measure of a student's judgment of their own abilities, was the strongest predictor of WTC $(\beta=.66)$, although there was a strong negative relationship $(\beta=-.90)$ with WTC made up of Predisposition against Verbal Behavior, which was comprised of Introversion and Communication Apprehension.

Another model proposed by Fushino (2008), focused on the effects of Co-operative Learning, especially attitudes towards group work in the classroom. The author selected this teaching method because it can increase student learning and encourage more learner autonomy. It was hypothesized that students with positive views of group work would participate more frequently and more positively in groups than students holding negative views toward group work. The results showed that Beliefs about Group Work directly predicted Communication Confidence in Group Work $(\beta=.49)$, which in turn predicted Willingness to Communicate in Groups $(\beta=.89)$. This study moved away from previous models as it was focused entirely on what happens inside the classroom without recourse to external factors.

In the last model, Peng and Woodrow (2010) investigated classroom constructs that affect WTC in the foreign language setting in China. The researchers predicted that a combination of Teacher Support, Student Cohesiveness, and Task Orientation would create a Classroom Environment that would impact on Learner Beliefs, WTC, and Communicative Confidence in English, and that Learner Beliefs would lead to Motivation, which in turn, would lead to Communicative Competence in the L2, and onto WTC. The results of the model are shown in Figure 2. Communicative Confidence was the strongest predictor of WTC $(\beta=.69)$. Unexpectedly, the significant path from Classroom Environment to WTC $(\beta=.18)$ was weak, perhaps as the authors speculated, because the students might have been unwilling to give negative appraisal of their teachers because of the importance of hierarchy in Chinese culture and the reverence afforded teachers. The researchers concluded that classroom contextual variables can be added to other individual variables to make a more complete model of WTC. 


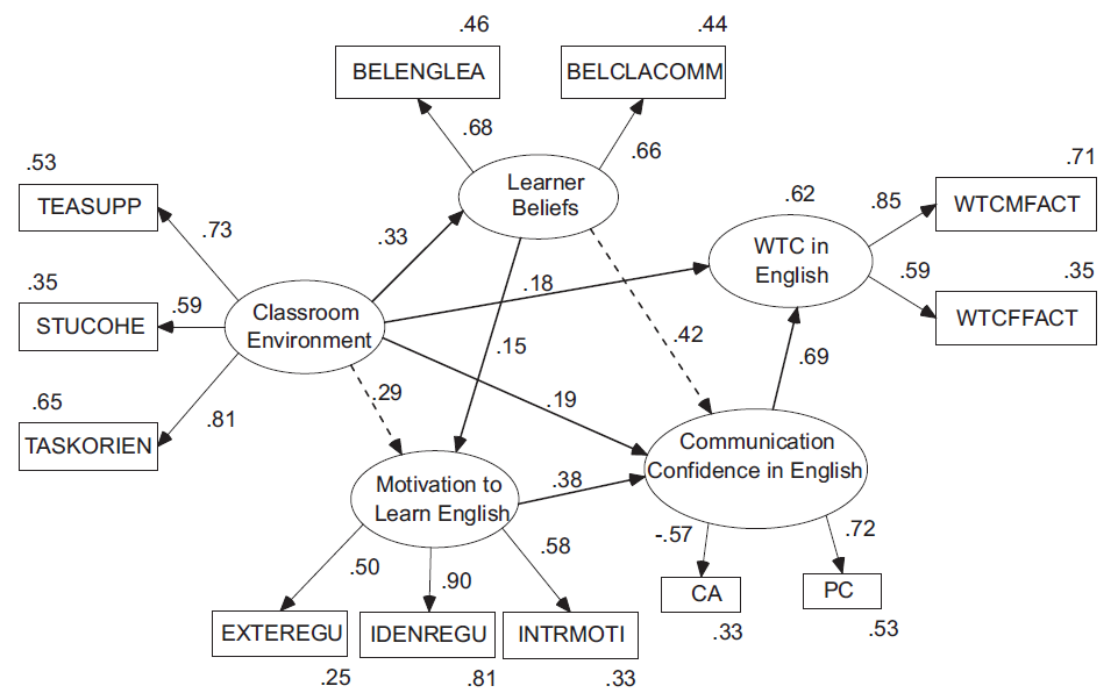

Figure 2. Model of Chinese WTC (Peng \& Woodrow, 2010, p. 853)

Note. WTCMFACT $=$ WTC in English Meaning-focused Activities; WTCFACT $=$ WTC in English in Form-focused Activities; $\mathrm{CA}=$ Communication Anxiety in English; $\mathrm{PC}=$ Perceived Communication Competence in English; EXTEREGU = External Regulation; IDENREGU = Identified Regulation; INTRMOTI $=$ Intrinsic Motivation; TEASUPP $=$ Teacher Support; STUCOHE $=$ Student Cohesiveness; TASKORIEN $=$ Task Orientation; BELENGLEA = Beliefs about English Learning; BELCLACOMM = Beliefs about Classroom Communication.

\subsection{Self-Reported WTC and Actual Communication}

Research into the construct of WTC has focused mainly on the intention to communicate, whether that is through trait or situational measures. Many studies have employed self-reported measures that seek to ascertain the Frequency of Communication that learners perceive they have engaged in (Baker \& MacIntyre, 2003; Clément, Baker, \& MacIntyre, 2003; Hashimoto, 2002; MacIntyre \& Charos, 1996). Other studies have used the trait WTC and a frequency measure that seeks to match communication situations that students may find themselves in during class and outside of class (Yashima et al., 2004), and other studies have used items that reflect class activities and real world activities students might engage in (MacIntyre \& Doucette, 2010). On the whole these studies have found that there is a significant, but low, correlation between the WTC construct and self-reported frequency measures (the models that these variables appear in reported pathways values of up to .33). Very few studies have used data from sources other than the students themselves.

In the L1 studies, through class observation, it was found students with higher trait WTC participated in class more than lower level WTC students (Chan \& McCroskey, 1987. Another study by MacIntyre, Babin, and Clément (1999), found that students significantly attended the voluntary laboratory tasks more if they had higher self-reported WTC.

From L1 to L2 studies, the author could only find three studies, all of which combined observation with self-report. In Hungary, Dörnyei, and Kormos (2000) compared the number of turns and their effect on two oral tasks with WTC as measured by an L1 instrument. It was found that the number of turns was significantly affected by L1 WTC. Second, after observation, Cao and Jiaotong (2012) found no correlation between number of turns and the length of turns of ESL students. Lastly, again through observation, Cao and Philp (2006), found no clear correlation between self-reported trait WTC and what was observed in the classroom for three situations of pair work, group and whole class settings in an ESL setting. These studies show that there needs to be more research to clarify the relationship between self-reported WTC and actual communication

In summary, a number of studies have found that situational variables involving the classroom environment can affect WTC. However, at the situational level many researchers still employ trait instruments, while only a few researchers have developed instruments that better fit what happens regarding classroom communication. The models that do employ situational variables are in the foreign language setting, with no situational models in second language setting currently available. Further, few studies have compared student-reported WTC with other more objective measures of actual communication from a source other than the students themselves. The 
intention to communicate by a learner should be compared to the actual amount of communication that takes place in order to validate the WTC instruments.

In keeping with quantitative methods started by other WTC researchers, this study aims to develop a reliable and valid structural model that explains part of the factors making up the classroom context in the L2 context. The variables and factors are few in number, but are all classroom-related variables focusing on communication, some of which have been developed for this study. The constructs are Classroom Situational Environment; Self-reported situational Willingness to Communicate; and Actual amount of Classroom Communication.

\section{Research Questions}

This study will address the following research questions:

- What are the relative strengths of the classroom-based factors among second language university students: Classroom Situational Environment; Communication Confidence (Communicative Anxiety and Self-Perceived Communicative Competence); Self-reported Willingness to Communicate?

- To what degree are Classroom Situational Environment; Communication Confidence (Communicative Anxiety and Self-Perceived Communicative Competence); Self-reported Willingness to Communicate and Teacher reported Frequency of Communicativeness related in a structural model?

\section{Methods}

\subsection{Participants}

The setting for this study is a university in the south of England, which will be referred to as PU from now. As well as the undergraduate courses, PU also offers an academic preparation course to help potential students reach the required level of proficiency to gain entrance onto the undergraduate course. This course lasts for 9 weeks, and is the source of the $n=$ size of 67 participants for this study. The number of participants is low, but comparable to other studies employing L2 WTC models (Hashimoto, 2002). During the academic preparation course students take courses in reading, listening, giving presentations and debate. The students themselves are characterized by a lower level of proficiency, and a full-range of affective variables, from those that are willing to take part in class activities to those that are not.

The student participant sample was broken down into gender, nationality, IELTS scores and experience abroad. First, the gender breakdown was $52 \%$ male and $48 \%$ female. Second, $90 \%$ of students were Chinese nationals, and the remaining $10 \%$ were a mix of European, South American and other Asian nationalities. Third, the majority of students had an IELTS score of 5.0, and the average score for the sample was 5.18, which means that the speaker can produce simple sentences with a high degree of fluency and accuracy (British Council, 2013). Lastly, most of the students had not spent time abroad before, but two students had spent six months previously in an English speaking country.

Along with the students, teachers on the academic courses also took part in the study. They were required to assign a communicative score for each student (discussed below). There are a total of ten teachers who teach the entire cohort of around 120 students in classes of about 12 students each. Of the 12 teachers, eight cooperated with this study. Seven of the eight are native English speakers and one is a native Chinese English speaker. All teachers have a lot of experience teaching ESL, and have taught on this particular academic course for a number of years. They all claim to use communicative methods in the class, which are based around building student confidence for class communication.

\subsection{Instruments and Model}

The instruments in this study are related specifically to spoken communication in the classroom. There were very few measures available from previous studies in their original form. Therefore, the instruments in this study were developed from a mixture of items from previous studies and new items that were piloted for the study. The proposed model can be seen in Figure 3. This model is based on data from a student questionnaire to measure the three constructs on the left side of the model, and a teacher rubric to measure the one construct on the right. 


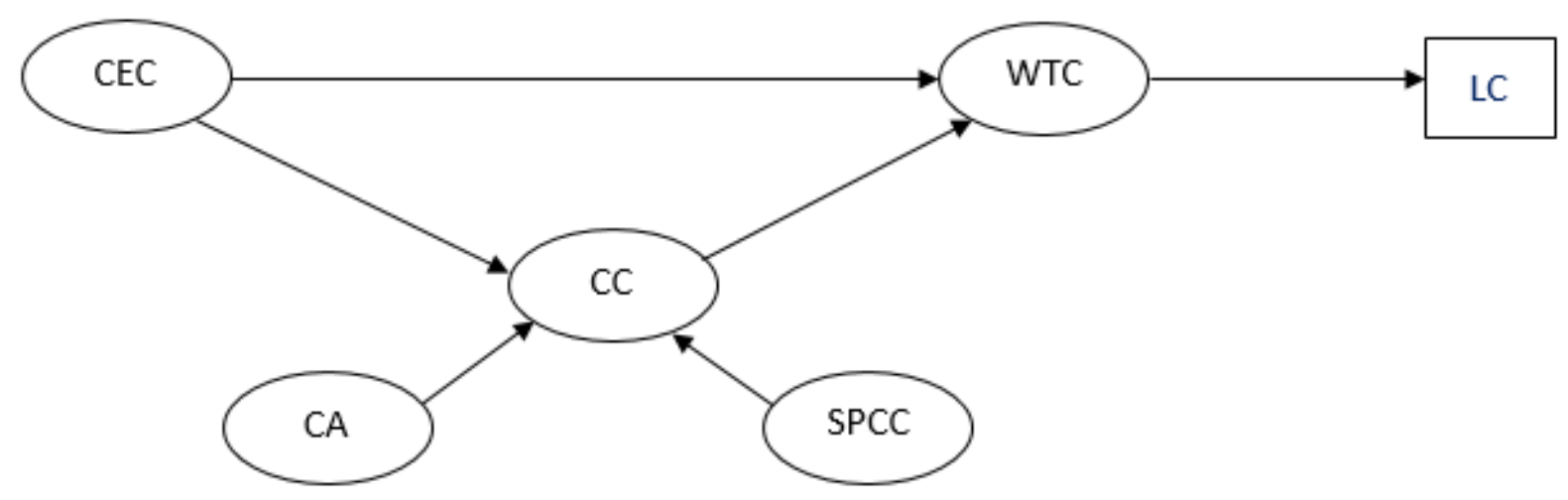

Figure 3. Situational model for WTC to be tested

Note. CEC: Classroom Environment for Communication; CA: Communication Anxiety; SPCC: Self-Perceived Communicative Competence; CC.: Communication Confidence; WTC: Willingness to Communicate; LC: Learner Communicativeness.

\subsubsection{Composition of Items in the Student Questionnaire}

The instruments used for this study can be seen in Appendix A. A six-point scale was used so that students would not be able to choose a neutral category (Brown, 2001). The main variables are:

Classroom Situational Environment: Classroom Situational Environment was made up of items that reflect the immediacy of communication in the classroom, namely items related to the teacher, tasks, group work and class atmosphere. The items were revised from studies by Horwitz (1987) and Peng and Woodrow (2010).

Communicative Confidence and WTC: Communicative confidence and WTC comprise of three variables, Communication Anxiety and Self-Perceived Communication Competence, which make up Communicative Confidence, and WTC. The items were piloted for this study, but follow a trend of creating a latent Communication Confidence factor through the combination of Perceived Competence and Communication Anxiety (Kim, 2004; Peng \& Woodrow, 2010; Yashima, 2002).

It was predicted that the classroom variables would lead to WTC directly and indirectly through Communicative Confidence. Further, the student-reported WTC would predict the Learner Communicativeness.

\subsubsection{Composition of Items in the Teacher Rubric}

To the best of the author's knowledge an instrument that measures Learner Communicativeness has not been developed for teachers or observers. The vast majority of instruments employed in WTC studies are designed to elicit student self-reported data. Few studies use a source other than students to measure classroom WTC. Those studies that do use methods such as observations have used specific counts of communicative instances for the study. For example in Cao (2006) the observation scheme included such actions as asking a teacher a question and volunteering an answer. Another study by Cao (2012) used the length of spoken interaction with six students over a period of four weeks. In the current study it is impractical to employ an observer to overlook all instances of communication in the class due to class size being around 12, in different classes.

The items in the rubric (Appendix B) were designed by the author with input from the teachers involved in this study. The purpose is to operationalize WTC as a product of student actions and intentions in the classroom. The rationale for equating classroom actions as participation comes from a study by Chan and McCroskey (1987) who used counts of participation in L1 classroom interaction among college students in the United States. Although the behaviors that the students exhibited were not mentioned, in this study those behaviors are defined as those that can indicate actual communication. Some of the behaviors came from a study by Bippus and Young (2000), who analyzed behaviors of class involvement among L1 university students in the United States.

Instead of addressing changes in WTC, the rubric used for this study was designed to give an overall communicative score for each student over the period of a 9-week course. This score might not reflect individual performances on specific days, but it is designed to produce a WTC score for each student that is representative of their communicativeness over the period. It is hoped that the accumulation of these events for each student will make the score reliable. The rubric showed examples of communicative behavior for students as follows: 5 $=A$ highly communicative student, $4=A$ communicative student, $3=A$ fairly communicative student, $2=$ 
Somewhat communicative, and $1=$ Generally not communicative.

\subsection{Procedure}

\subsubsection{Student Questionnaire}

Students were initially directed by the instructors on the course to fill out a questionnaire on-line around weeks four to six of the course, which it was made clear was optional. The reply of this on-line instrument was poor, so the author requested the teachers to issue a paper version to students in class, which were collected by the program coordinator around week six.

\subsubsection{Teacher Rubric}

Teachers who participated in this study attended a meeting around week three of the 9-week course. At that meeting the author explained how the rubric worked and answered any questions about its use. The teachers, using the rubric gave an individual score for each student in their class at the end of the nine-week course, which was sent to the author in an email.

\section{Results}

PASW Statistics 18.0 (SPSS Inc., 2009) was used to investigate the factors. The statistical assumptions of the data were checked. Some evidence of negative skewness was found for one item and positive skewness was observed in two items. An inspection of the normal distributions in PASW revealed minor deviations from the normal and these items were deemed acceptable for the analysis. Apart from these three items, the rest of the data set was inside acceptable limits of both skewness and kurtosis. The factor analysis for these factors can be seen in Table 1.

Table 1. Factor analysis for four situational constructs

\begin{tabular}{|c|c|c|c|c|c|}
\hline & $\mathrm{CA}$ & SPCC & WTC & CEC & $h^{2}$ \\
\hline w12 & .773 & & & & .715 \\
\hline w27 & .744 & & & & .722 \\
\hline w32 & .716 & & & & .649 \\
\hline w18 & & .771 & & & .801 \\
\hline w20 & & .707 & & & .595 \\
\hline w31 & & .624 & & & .574 \\
\hline w8 & & & .645 & & .684 \\
\hline w11 & & & .618 & & .695 \\
\hline w24 & & & .598 & & .581 \\
\hline w33 & & & .522 & & .575 \\
\hline w1 & & & & .758 & .758 \\
\hline w3 & & & & .736 & .708 \\
\hline w4 & & & & .681 & .645 \\
\hline w5 & & & & .635 & .606 \\
\hline w7 & & & & .581 & .469 \\
\hline w10 & & & & .495 & .451 \\
\hline Variance (\%) & 36.36 & 11.24 & 7.26 & 4.51 & 59.37 \\
\hline Reliability & .86 & .82 & .81 & .79 & \\
\hline
\end{tabular}

Note. CEC: Classroom Environment for Communication; CA: Communication Anxiety; SPCC: Self-Perceived Communicative Competence; WTC: Willingness to Communicate.

A factor analysis was carried out on the data using the Generalized Least Squares Method with Oblimin rotation to determine the underlying factors. After checking the Eigen values above 1.0, four clear factors were found. The four factors in Table 1 accounted for $59.37 \%$ of the variance, with the items loading well onto their individual factors. There were no complex items that loaded over 4.0 on more than one factor. Further, communality values for items and reliability of the four factors were satisfactory.

The final analysis in this paper is the confirmation of the proposed structural model. This is performed through a statistical process called Structural Equation Modeling (SEM), carried out through the software EQS 6.2 (Bentler, 2006) to test the hypothesized structural model.

The resulting structural model from the data set in this study is seen in Figure 4. Attention is given to the fit 
statistics that show if the hypothesized model is a credible representation of the relationship between the factors. After checking the fit statistics for this model, it was found that the Root Mean Square Error of Approximation (RMSEA), which was .08, corresponding to a mediocre fit to the data (Byrne, 2006). The Comparative Fit Index (CFI) was .89, again indicating a reasonable fit to the data (Hu \& Bentler, 1999).

Along with the fit statistics, the relationships between the significant paths between the factors are given. As predicted the Classroom variables predicted WTC directly $(\beta=.42)$, Communicative Confidence $(\beta=.58)$, which lead to WTC $(\beta=.70)$. Further the WTC predicted the amount of Learner Communicativeness, as measured by the teacher rubric $(\beta=.90)$. Lastly, Communicative Confidence was predicted by Self-Perceived Communicative Competence $(\beta=.78)$ and Communicative Anxiety $(\beta=.22)$. These weights are indicative of strong causal relationships between the variables.

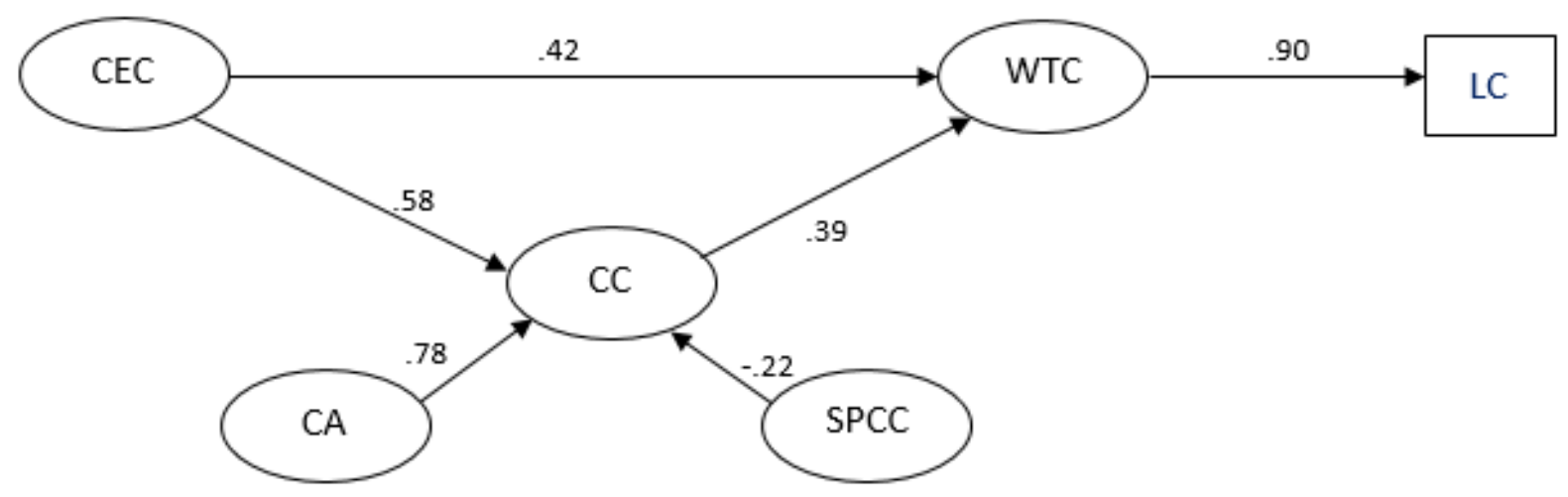

Figure 4. Final structural model of situational WTC

Note. CEC: Classroom Environment for Communication; CA: Communication Anxiety; SPCC: Self-Perceived Communicative Competence; Com. Conf.: Communication Confidence; WTC: Willingness to Communicate; LC: Learner Communicativeness.

\section{Discussion}

From the data analysis, attention can be turned to the two research questions posited for this study. First, the relative strengths of the factors in this study can be confirmed by the high factor scores exhibited for each variable on its hypothesized factor. Many of the items in this study were piloted from scratch, so their reliability and validity needed to be established. All the constructs factored strongly as seen in other studies using trait measures (Kim, 2004; Yashima, 2002; Yashima et al., 2004) and those using situational measures (Fushino, 2008; MacIntyre et al., 2010). Next, the WTC compromised of new items, and was found to factor reliably. Further, a new factor called Classroom Environment for Communication factored to a high degree. This factor employed some of the items from Peng and Woodrow, (2010), whose population was, as with the majority in this study, Chinese students. These distinct factors, and the fact that they made up $59.37 \%$ of the variance, are powerful components of situational WTC and showed a good level of validity.

Next, the structural model in Figure 4 answered the second research question. The model fit values were acceptable. A combination of classroom atmosphere, including the actions of the teacher, the task, and the use of group work can help to create WTC. The classroom factor also has similarities to the ideas espoused in the communicative method (Nunan, 1991). This lends support to the notion that Communicative Language Teaching (CLT) can affect WTC in the classroom, which has already been found in foreign language settings (Aubrey, 2010). Further the model showed self-reported WTC predicted Actual Communication as indicated by the path value of $\beta=.90$. Studies have found a correlation between self-report WTC and self-report of actual use. The teacher as a source of information is invaluable as he/she observe learners over an extended period, making their score true representations of actual communication in class. If self-report correlates highly with communicativeness, the overall construct validity of WTC is vindicated and the teacher should be used more often as a source of measuring the construct of WTC.

\section{Conclusions}

The results in the present study offer avenues for future research. First, the importance of classroom variables 
that lead to WTC has been proven. The classroom is important not only in foreign language settings, but also second language contexts, like the context in the current study. In future research, classroom constructs should be tested as separate factors, and combined with other constructs to make a complete situational model. Second, this study utilizes a valuable resource for researching WTC, namely the teacher. This teacher score, however, would involve more time and effort on the part of the teacher to collect, so explaining of the benefits of measuring communicativeness as a diagnostic tool or research tool should be emphasized. Without teachers' cooperation, any future endeavors of this kind will be unrealized. The author of this study believes that a teacher score, along with self-reported WTC and other constructs can all combine to make measurement of situational WTC more accurate and valid.

\section{Acknowledgements}

The data collection in this study would not have been possible without the help of all teachers and administrators on the pre-sessional course at PU, Hampshire, England.

\section{References}

Aubrey, S. C. (2010). Influences on Japanese students' willingness to communicate across three different sized EFL classes. Asian EFL Journal. Retrieved June 20, 2012, from http://www.asian-efl-journal.com/Thesis/Thesis-Aubrey.pdf

Baker, S. C., \& MacIntyre, P. D. (2003). The role of gender and immersion in communication and second language orientations. Language Learning, 53(1), 65-96. http://dx.doi.org/10.1111/0023-8333.00224

Bentler, P. M. (2006). EQS 6 Structural Equations Program Manual. Encino, CA: Multivariate Software Inc.

Bippus, A. M., \& Young, S. L. (2000). What behaviors reflect involvement in a course?: Students' perceptions and differences between high and low communication apprehensive. Communication Research Reports, 17(3), 310-319. http://dx.doi.org/10.1080/08824090009388778

British Council. (2013). IELTS Speaking band descriptors (public version). Retrieved September 20, 2013, from http://www.britishcouncil.org/srilanka-exams-ielts-descriptor-speaking.pdf

Brown, J. D. (2001). Using Surveys in Language Program. Cambridge: Cambridge University Press.

Byrne, B. M. (2006). Structural Equation Modeling with EQS. Basic concepts, applications, and programming (2nd ed.). New York: Lawrence Erlbaum Associates, Inc.

Cao, Y., \& Jiaotong, X. (2012). Willingness to communicate and communication quality in ESL classrooms. TESL Reporter, 45(1), 17-36.

Cao, Y., \& Philp, J. (2006). Interactional context and willingness to communicate: A comparison of behavior in whole class, group and dyadic interaction. System, 34(4), 480-493. http://dx.doi.org/10.1016/j.system.2006.05.002

Chan, B., \& McCroskey, J. C. (1987). The WTC scale as a predictor of classroom participation. Communication Research Reports, 4(2), 47-50. Retrieved November 20, 2014, from http://www.jamescmccroskey.com/publications/138.pdf

Clément, R., Baker, S. C., \& MacIntyre, P. D. (2003). Willingness to communicate in a second language: The effects of context, norms and vitality. Journal of Language and Social Psychology, 22(2), 190-209. http://dx.doi.org/10.1177/0261927X03022002003

Dörnyei, Z., \& Kormos, J. (2000). The role of individual and social variables in oral task performance. Language Teaching Research, 4(3), 275-300. http://dx.doi.org/10.1177/136216880000400305

Fushino, K. (2009). Measuring Japanese university students' readiness for second-language group work and its relation to willingness to communicate. Dissertation Abstracts International Section A: Humanities and Social Sciences, 69(8-A), 3009.

Gardner, R. C. (1985). Social Psychology and Second Language Learning: The role of attitudes and motivation. London: Edward Arnold.

Hashimoto, Y. (2002). Motivation and willingness to communicate as predictors of reported L2 use: The Japanese ESL context. Second Language Studies, 20(2), 29-70. Retrieved September 6, 2012, from http://www.hawaii.edu/sls/uhwpesl/20(2)/Hashimoto.pdf

Horwitz, E. K. (1987). Surveying student beliefs about language learning. In A. Wenden, \& J. Rubin (Eds.), Learner strategies in language learning (pp. 119-132). New York: Prentice Hall. 
Hu, L. T., \& Bentler, P. M. (1999). Cutoff criteria for fit indexes in structure analysis: Conventional criteria versus new alternatives. Structural Equation Modeling, 6(1), 1-55.

Kang, S. (2005). Dynamic emergence of situational willingness to communicate in a second language. System, 33, 277-292. doi:10.1016/j.system.2004.10.004

Kim, S. J. (2004). Exploring willingness to communicate (WTC) in English among Korean EFL (English as a foreign language) students in Korea: WTC as a predictor of second language communication (Unpublished Doctorial dissertation). Ohio State University, Columbus.

MacIntyre, P. D. (1994). Variables underlying willingness to communicate: A causal analysis. Communication Research Reports, 11(2), 135-142. http://dx.doi.org/10.1080/08824099409359951

MacIntyre, P. D., \& Charos, C. (1996). Personality, attitudes, and affect as predictors of second language communication. Journal of Language and Social Psychology, 15, 3-26. http://dx.doi.org/10.1177/0261927X960151001

MacIntyre, P. D., \& Doucette, J. (2010). Willingness to communicate and action control. System, 38(2), 161-171. http://dx.doi.org/10.1016/j.system.2009.12.013

MacIntyre, P. D., Babin, P. A., \& Clément, R. (1999). Willingness to communicate: Antecedents \& consequences. Communication Quarterly, 47(2), 215-229. http://dx.doi.org/10.1080/01463379909370135

MacIntyre, P. D., Clément, R., Dörnyei, Z., \& Noels, K. (1998). Conceptualizing willingness to communicate in a L2: A situational model of L2 confidence and affiliation. Modern Language Journal, 82(4), 545-562. http://dx.doi.org/10.1111/j.1540-4781.1998.tb05543.x

Matsuoka, R. (2005). Japanese college students' willingness to communicate in English. Temple University Dissertations.

McCroskey, J. C., \& Baer, J. E. (1985, November). Willingness to communicate: The construct and its measurement. Paper presented at the annual convention of the Speech Communication Association, Denver, $\mathrm{CO}$.

Nunan, D. (1991). Language teaching methodology: A textbook for teachers. London: Prentice Hall.

Oxford, R. L., \& Shearin, J. (1994). Language learning motivation: expanding the theoretical framework. Modern Language Journal, 78, 12-28. http://dx.doi.org/10.1111/j.1540-4781.1994.tb02011.x

Peng, J. E., \& Woodrow, L. (2010). Willingness to communicate in English: A model in the Chinese EFL $\begin{array}{lllll}\text { classroom } \quad \text { context. } & \text { Language } & \text { Learning, } & \text { 80(4), }\end{array}$ http://dx.doi.org/10.1111/j.1467-9922.2010.00576.x

Spss Inc. (2009). PASW Statistics for Windows, Version 18.0. Chicago: SPSS Inc.

Tabachnick, B. G., \& Fidell, L. S. (2007). Using Multivariate Statistics (5th ed.). New York: Allyn and Bacon.

Weaver, C. (2010). Japanese university students' willingness to use English with different interlocutors. Temple University Dissertations.

Wen, W. P., \& Clément, R. (2003). A Chinese conceptualization of willingness to communicate in ESL. Language, Culture and Curriculum, 16(1), 18-38. http://dx.doi.org/10.1080/07908310308666654

Yashima, T. (2002). Willingness to communicate in a second language: The Japanese EFL context. Modern Language Journal, 86, 54-66. http://dx.doi.org/10.1111/1540-4781.00136

Yashima, T., Nishide, L. Z., \& Shimizu, K. (2004). The influence of attitudes and affect on willingness to communicate and second language communication. Language Learning, 54(1), 119-152. http://dx.doi.org/10.1111/j.1467-9922.2004.00250.x

\section{Appendix A}

\section{Items Used in the Present Study}

\section{CEC-Classroom Environment for Communication}

(1) Speaking activities in the pre-sessional classes are useful for my future.

(3) The teacher is patient with the students.

(4) The pre-sessional class atmosphere is fun.

(5) The teacher encourages us to speak out in pre-sessional classes. 
(7) It's important students help each other when we are trying to communicate in English.

(10) Speaking activities in my pre-sessional classes are interesting.

\section{SPCC-Self-Perceived Communicative Competence}

(18) My English speaking level is OK for my pre-sessional classes.

(20) I can make a conversation with someone in English.

(31) I think I am good at speaking English in class.

\section{CA-Communicative Anxiety}

(12) I am worried that other students will think my English speaking is not so good.

(27) I'd feel a little embarrassed if I'm not good at speaking English in class.

(32) I feel unhappy if other students cannot understand my English in class.

\section{WTC-Willingness to Communicate}

(8) I will volunteer my answers during the pre-sessional course.

(11) I look forward to speaking in my pre-sessional classes.

(24) I like speaking English in pre-sessional classes.

(33) I will say my opinions in the pre-sessional classes.

\section{Appendix B}

\section{Teacher Assessment of Learner communicativeness}

You are instructed to (1) not be concerned with the quality of the students speaking (e.g., their grammatical accuracy) or any behavioral issues, and (2) focus on the quantity of their English participation and communicativeness in the class.

\section{5 = EXCELLENT A highly communicative student}

- speaking frequency was well above expectations

- often made comments or asked questions during tasks to other students / teacher in class

- often made casual conversation in English with students / the teacher

- took a highly active role in speaking tasks

- appeared highly motivated to speak

- often volunteered answers in a whole class setting

- Took part actively in group settings

\section{$4=$ GOOD A communicative student}

- speaking frequency was somewhat above expectations

- sometimes made comments or asked questions during tasks to other students / teacher in class

- often made casual conversation in English with students / the teacher

- took an active role in speaking tasks

- appeared motivated to speak

- sometimes volunteered answers in a whole class setting

- Took part actively in group settings

\section{$3=$ FAIR A fairly communicative student}

- speaking frequency was minimally acceptable

- sometimes made comments or asked questions during tasks to other students

- made occasional casual conversation in English with students

- participated in speaking tasks, meeting the basic requirements

- appeared marginally motivated to speak

- volunteered answers in a whole class setting once or twice

- Took part a little in group settings

\section{$2=$ POOR Somewhat communicative}

- speaking frequency was below expectations

- rarely made comments or asked questions to other students 
- $\quad$ rarely engaged in casual conversation with other students

- generally inactive during speaking tasks

- $\quad$ appeared to have little motivation to speak

- did not volunteer answers in class

- Poor work participation in group settings

\section{$1=$ VERY POOR Generally not communicative}

- $\quad$ speaking frequency was well below expectations

- almost never made comments, or asked questions to other students

- rarely spoke during speaking tasks, even when required to do so

- $\quad$ appeared unmotivated to speak

- did not volunteer answers in class

- did not take part in group setting

\section{Copyrights}

Copyright for this article is retained by the author(s), with first publication rights granted to the journal.

This is an open-access article distributed under the terms and conditions of the Creative Commons Attribution license (http://creativecommons.org/licenses/by/3.0/). 